\title{
An “Ancient” Schwannoma of Cervical Region
}

\author{
Nataraj Rajanala Venkata1, Mazhar Aslam Dodhia² \\ ${ }^{1}$ Grant Government Medical College, Mumbai, India \\ ${ }^{2}$ Department of Surgical Oncology, Nanavati Superspeciality Hospital, Ville Parle, Mumbai \\ Email: nataraj.rv@gmail.com
}

How to cite this paper: Venkata, N.R. and Dodhia, M.A. (2020) An “Ancient" Schwannoma of Cervical Region. International Journal of Otolaryngology and Head \& Neck Surgery, 9, 8-13.

https://doi.org/10.4236/ijohns.2020.91002

Received: December 10, 2018

Accepted: December 3, 2019

Published: December 6, 2019

Copyright $\odot 2020$ by author(s) and Scientific Research Publishing Inc. This work is licensed under the Creative Commons Attribution International License (CC BY 4.0).

http://creativecommons.org/licenses/by/4.0/

\begin{abstract}
Schwannoma is a benign encapsulated neoplasm which grows slowly. It originates from Schwann cells, the sheath cells that cover the myelinated nerve fibers. Head and Neck regions account for around 25\% - 40\% of the cases. Ancient schwannoma is a rare variant wherein degenerative change occurred in a long-standing schwannoma. This causes sudden increase in size and pain, mimicking a malignant change. It was first described by Ackerman and Taylor in 1951. In this article, I would like to present a case of Ancient variant of Cervical Schwannoma.
\end{abstract}

\section{Keywords}

Schwannoma, Cervical Swelling, Ancient Variant

\section{Introduction}

Schwannomas are benign encapsulated tumors that arise from the Schwann Cells, the cells which cover the myelinated nerve [1]. Schwannomas that occur in the head and neck region constitute around 25\% - 40\% [2]. The most nerves involved in head and neck region are the Vagus nerve and the Sympathetic Chain [3]. Based on the histological profile, five different subtypes are described: ancient, glandular, melanotic, cellular, psammomatous melanotic schwannoma [4]. "Ancient" term is proposed for long-standing neural tumours, which has undergone degenerative changes and focal calcifications [4]. It has been proposed that, in long-standing schwannomas, due to progressive increase in size, vascular insufficiency occurs leading to degenerative changes and focal calcifications [5].

This results in a sudden increase in size of the swelling and pain, mimicking malignant change. Microscopically, schwannomas are encapsulated, solid or cystic tumours. They can be composed of two cellular zones: Antony type A, densely arranged with spindle-shaped Schwann cells and areas of palisading 
nuclei, and Antony B, characterized by a hypocellular arrangement and a large quantity of myxoid tissue [6]. However, the ancient variant is characterized by degenerative changes typified by perivascular hyalinization, calcification, cystic necrosis, relative loss of Antoni type A tissue, and degenerative nuclei that may be misinterpreted as sarcomatous pleomorphisms. However, the absence of mitosis and the presence of cystic necrosis and a well-defined capsule without surrounding invasion help to differentiate these lesions from high-grade lesions. Contrast Enhanced CT (CECT) Scan and MRI [7] [8] usually delineate the lesion well. Surgical excision of the mass with preservation of the parent nerve is the treatment of choice.

We present a case of Left Cervical Schwannoma which was diagnosed as the ancient variant upon histological examination.

\section{Case Report}

A 36-year-old male presented to us with complaints of painless mass over left side of neck, which was slow growing but had rapidly increased in size over past few weeks. There were no associated complaints like persistent cough or hoarseness of voice. His medical history was unremarkable. On clinical examination, a mass was found in the right level 2 cervical region; deep to the SCM muscle, around $3 \times 3 \mathrm{cms}$ in diameter, smooth surfaced, mobile in the horizontal plane, firm, and painless. Upon palpating the mass pulsations were felt but no murmur was heard on auscultation of the mass. Medial displacement of peritonsillary structures was not observed in the oropharyngeal examination. All the cranial nerve examinations were normal. Contrast Enhanced CT (Figure 1) demonstrated a well-circumscribed mass in the left carotid space, splaying the carotids and causing compression of left IJV. Since there was no post-contrast enhancement of the mass, Carotid Body tumor was ruled out. FNAC was done and diagnosis of Schawannoma was made. The patient was the posted for surgery. The neck was explored by a transverse left skin incision. Deep to the upper portion of the sternocleidomastoid muscle, an encapsulated, $3 \times 2 \mathrm{~cm}$ tumour was found between the internal and external carotid artery anteromedially, and the internal jugular vein posterolaterally. Vagus nerve was seen running superficial to the mass (Figure 2).

The eccentric site of the mass and the presence of a capsule (Figure 3) indicated that it was probably a benign lesion. The mass was carefully dissected from the nerve and the vagus nerve was preserved.

The post-operative period was uneventful. The patient developed mild paresis of the left vocal cord which recovered in due course. Histopathological examination (Figure 4) revealed a tumour mass composed of mainly spindle- to oval-shaped cells in a myxoid background suggestive of schwannoma. Mitotic figures were absent and focal areas of calcification noted. Alternate areas of hypercellular (Antoni A) and hypocellular (Antoni B) were also seen. All the above features lead to diagnosis of an Ancient Variant of Schwannoma. The 


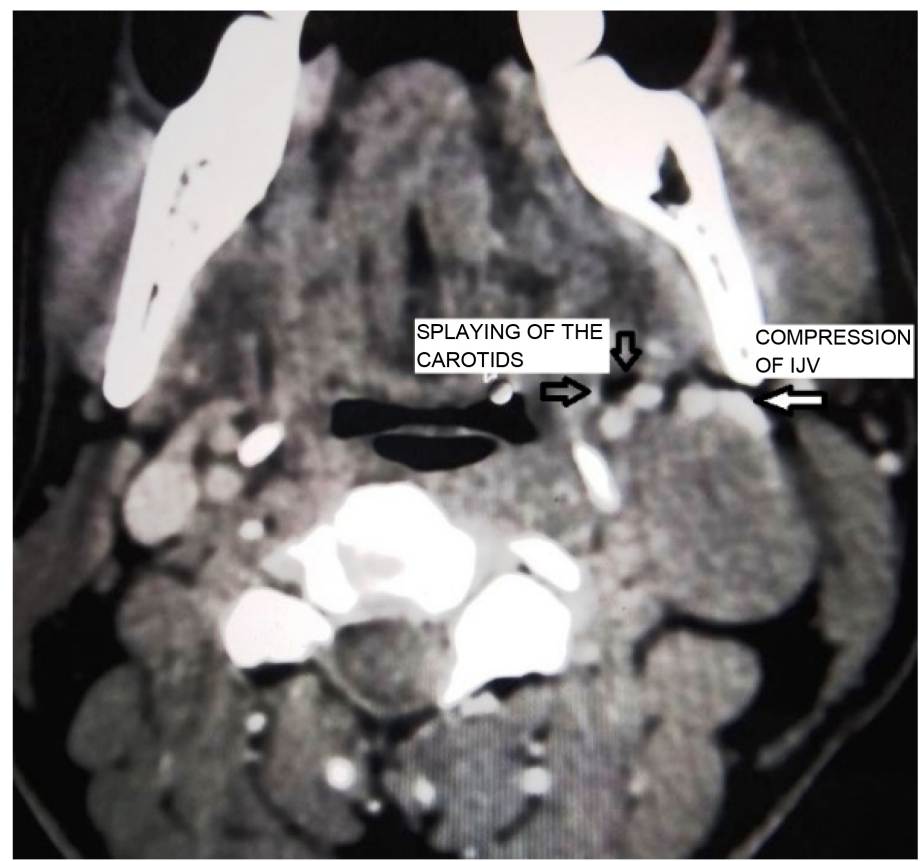

Figure 1. CT Scan showing splaying of the carotids and compression of IJV by the mass.

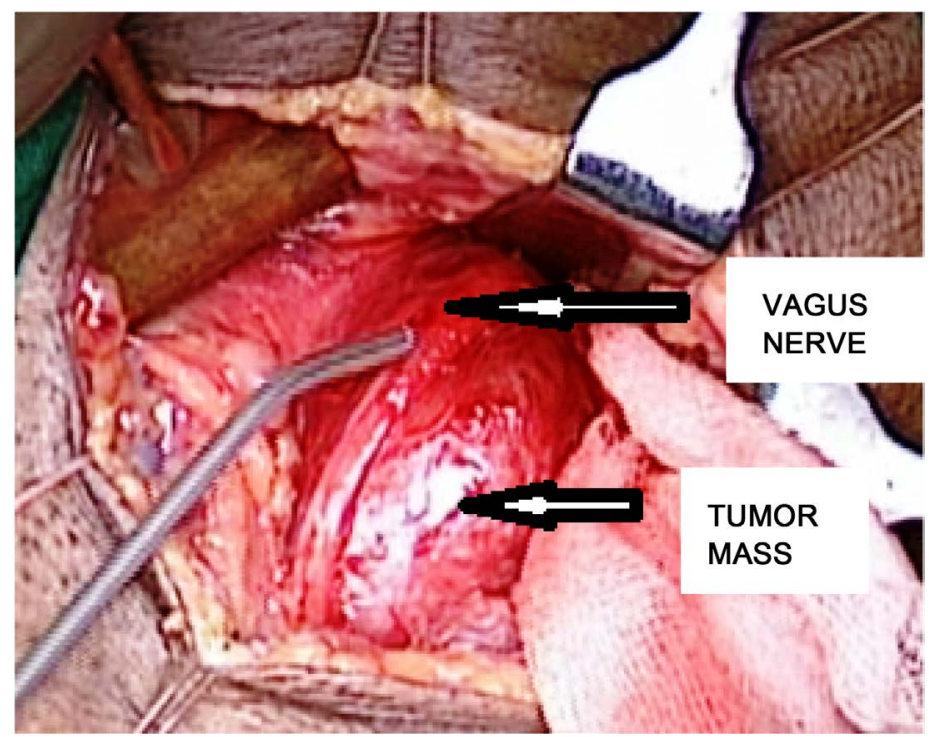

Figure 2. Location of the tumor mass below the vagus nerve.

six-month postoperative follow-up was uneventful.

\section{Discussion}

A schwannoma is a benign nerve sheath tumor composed of schwann cells, which normally produce the insulating myelin sheath covering the peripheral nerves [9]. Schwannomas are equally seen in both genders in their third and fourth decades of life [10]. It is mostly asymptomatic, encapsulated, lobulated with smooth margin and remains peripherally attached to at least one nerve 


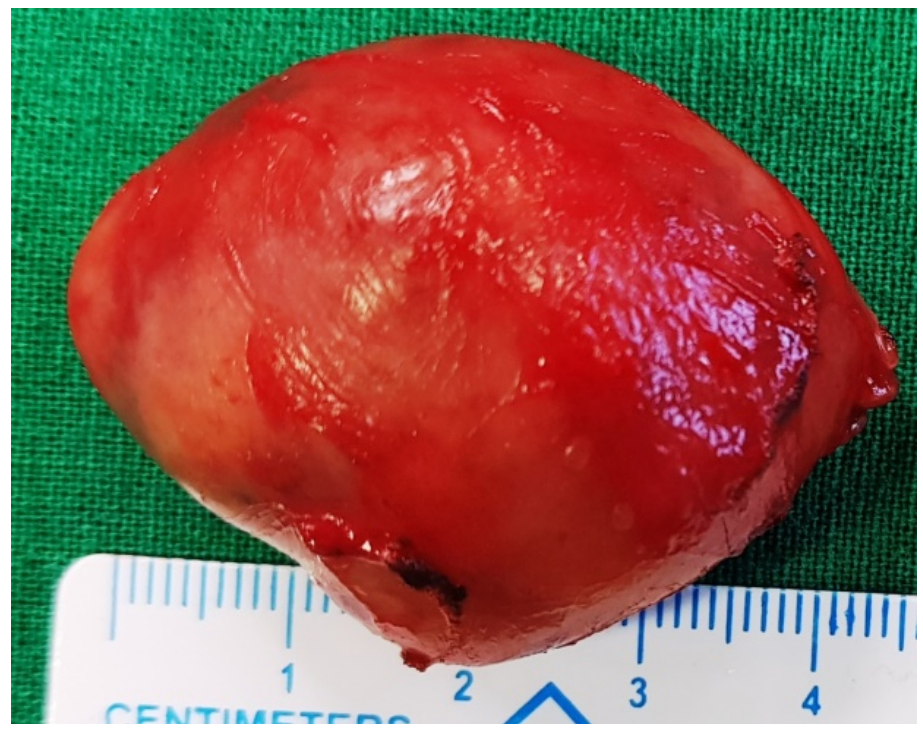

Figure 3. A well-encapsulated mass was excised completely.

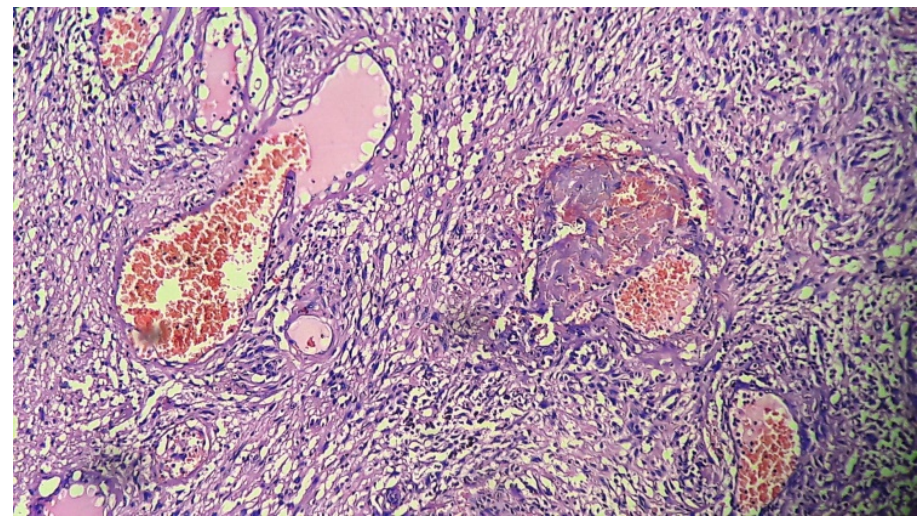

Figure 4. Histopathological examination showed Antoni A and Antoni B areas.

root. Schwannoma of vagus is more commonly reported on the left side compared to the right, as seen in the present case [11] [12]. Most schwannomas are fairly homogeneous soft tissue masses and appear hypodense or isodense to skeletal muscle on non-contrast $\mathrm{CT}$ and tend to be hypointense or isointense to skeletal muscle on T1-weighted MR images and variably hyperintense on T2-weighted images. Despite their hypovascularity, they enhance significantly on both CT and MR images and can mimic a paraganglioma. The enhancement of the schwannomas is seen at least 2 minutes after the contrast injection and depicts the equilibrium phase of the contrast agent and the poor venous drainage of the tumor. Dynamic scans can reveal the true nature of the lesion and differentiate it from hypervascular lesions. The enhancement pattern of neural tumors can vary; it may be an inhomogeneous enhancement (owing to necrosis and hemorrhage) or even lack of enhancement [9]. Ancient schwannoma, a degenerative neurilemmoma, a rare variant of schwannoma first described by Ackerman and Taylor in 1951 [13], is a schwannoma subtype characterized by 
degeneration and diffuse hypocellular areas. These changes are believed to occur because it takes a long time for schwannomas to develop [14]. The radiologic findings for ancient schwannoma are similar to those for schwannoma, which on contrast-enhanced computed tomography shows enhancement in capsules or pericystic areas [7]. It is characterized by degenerative changes typified by perivascular hyalinization, calcification, cysticnecrosis, relative loss of Antoni type A tissue, and degenerative nuclei that may be misinterpreted as sarcomatous pleomorphisms. However, the absence of mitosis and the presence of cystic necrosis and a well-defined capsule without surrounding invasion help to differentiate these lesions from high-grade lesions [7] [8]. Ancient schwannomas are benign tumors and the goal of treatment is complete excision with possible preservation of the involved nerve as complete resection is usually curative with a good prognosis [15].

\section{Conflicts of Interest}

The authors declare no conflicts of interest regarding the publication of this paper.

\section{References}

[1] Sufian, Z., Mazhar, A., Lateef, J.Z. and Rana, S.K. (2009) Intraosseous Schwannoma of Head of First Metatarsal: A Rare Entity. Indian Journal of Pathology and Microbiology, 52, 286-288. https://doi.org/10.4103/0377-4929.48954

[2] Bayindir, T., Kalcioglu, M.T., Kizilay, A., Karadag, N. and Akarcay, M. (2006) Ancient Schwannoma of the Parotid Gland: A Case Report and Review of the Literature. Journal of Cranio-Maxillofacial Surgery, 34, 38-42. https://doi.org/10.1016/j.jcms.2005.08.003

[3] Furukawa, M., Furukawa, M.K., Katoh, K. and Tsukuda, M. (1996) Differentiation between Schwannoma of the Vagus Nerve and Schwannoma of the Cervical Sympathetic Chain by Imaging Diagnosis. Laryngoscope, 106, 1548-1552. https://doi.org/10.1097/00005537-199612000-00021

[4] Lin, J. and Martel, W. (2001) Cross-Sectional Imaging of Peripheral Nerve Sheath Tumors Characteristic Signs on CT, MR Imaging, and Sonography. American Journal of Roentgenology, 176, 75-82. https://doi.org/10.2214/ajr.176.1.1760075

[5] Choudry, H.A., Nikfarjam, M., Liang, J.J., Kimchi, E.T., Conter, R., Gusani, N.J., et al. (2009) Diagnosis and Management of Retroperitoneal Ancient Schwannomas. World Journal of Surgical Oncology, 7, Article No. 12. https://doi.org/10.1186/1477-7819-7-12

[6] Neville, B.W., Damm, D.D., Allen, C.M., et al. (1995) Soft Tissue Tumors. In: Oral \& Maxillofacial Pathology, WB Saunders, Philadelphia, 362-415.

[7] Isobe, K., Shimizu, T., Akahane, T. and Kato, H. (2004) Imaging of Ancient Schwannoma. American Journal of Roentgenology, 183, 331-336. https://doi.org/10.2214/ajr.183.2.1830331

[8] Kagaya, H., Abe, E., Sato, K., Shimada, Y. and Kimura, A. (2000) Giant Cauda Equina Schwannoma: A Case Report. Spine, 15, 268-272. https://doi.org/10.1097/00007632-200001150-00021

[9] Vogl, T. and Bisdas, S. (2009) Cervical Adenopathy and Neck Masses. In: Haaga, 
J.R., Dogra, V.S., Forsting, M., Gilkeson, R.C., Ha, H.K. and Sundaram, M., Eds., $C T$ and MRI of the Whole Body, 5th Edition, Mosby Elsevier, Philadelphia, 664-665. https://doi.org/10.1016/B978-0-323-05375-4.50017-3

[10] Strollo, D.C., Rosado-de-Christenson, M.L. and Jett, J.R. (1997) Tumors of the Middle and Posterior Mediastinum. Chest, 112, 1344-1357. https://doi.org/10.1378/chest.112.5.1344

[11] Menal, P., Garcia, F. and Rivas, J.J. (2011) Intrathoracic Vagal Nerve Schwannoma. Archivos De Bronconeumología, 47, 374-375. https://doi.org/10.1016/j.arbr.2011.02.005

[12] Rammos, K.S., Rammos, S.K., Foroulis, C.N. and Zaramboukas, T.K. (2009) Schwannoma of the Vagus Nerve, a Rare Middle Mediastinal Neurogenic Tumor: Case Report. Journal of Cardiothoracic Surgery, 4, Article No. 68.

https://doi.org/10.1186/1749-8090-4-68

[13] Ackerman, L.V. and Taylor, F.H. (1951) Neurogenous Tumors within the Thorax: A Clinicopathological Evaluation of Forty-Eight Cases. Cancer, 4, 669-691. https://doi.org/10.1002/1097-0142(195107)4:4<669::AID-CNCR2820040405>3.0.C $\underline{\mathrm{O} ; 2-\mathrm{B}}$

[14] Dahl, I. (1977) Ancient Neurilemmoma (Schwannoma). Acta Pathologica et Microbiologica Scandinavica, 85, 812-818. https://doi.org/10.1111/j.1699-0463.1977.tb03896.x

[15] Ugokwe, K., Nathoo, N., Prayson, R. and Barnett, G.H. (2005) Trigeminal Nerve Schwannoma with Ancient Change. Case Report and Review of the Literature. Journal of Neurosurgery, 102, 1163-1165. https://doi.org/10.3171/jns.2005.102.6.1163 